\title{
Growth, Body Composition, and Neurodevelopmental Outcomes at 2 Years Among Preterm Infants Fed an Exclusive Human Milk Diet in the Neonatal Intensive Care Unit: A Pilot Study
}

\author{
Erynn M. Bergner,, ${ }^{1,2}$ Roman Shypailo, ${ }^{3}$ Chonnikant Visuthranukul, ${ }^{1,3-5}$ Joseph Hagan, ${ }^{1}$ \\ Andrea R. O'Donnell, ${ }^{1}$ Keli M. Hawthorne, ${ }^{6}$ Steven A. Abrams, ${ }^{6}$ and Amy B. Hair ${ }^{1}$
}

\begin{abstract}
Background: Long-term outcomes of preterm infants fed an exclusive human milk-based (EHM) diet using a donor human milk-based fortifier are not well defined.

Materials and Methods: Infants $\leq 1,250 \mathrm{~g}$ birth weight (BW) were studied prospectively at two outpatient visits: 12-15 and 18-22 months corrected age (CA). Dual-energy X-ray absorptiometry and Bayley Scales of Infant and Toddler Development III (BSID-III) were performed at 18-22 months CA.

Results: In this pilot study, 51 preterm infants (gestational age $27.8 \pm 2.6$ weeks and BW $893 \pm 204 \mathrm{~g}$ ) were evaluated. While anthropometric z-scores were significantly lower at discharge compared with birth, z-scores returned to birth levels by 12-15 months CA (length and head circumference [HC]) and 18-22 months CA (weight). Body composition at 2 years of age was similar to term-matched controls. Inpatient growth was significantly correlated with bone density, lean mass (LM), and fat-free mass at 18-22 months CA. Increased mother's own milk (MOM) was significantly correlated with decreased fat mass indices. BSID-III showed that $0 \%$ of cognitive composite scores were $<70$.

Conclusions: In addition to returning to BW, length, and $\mathrm{HC}$ z-scores by 2 years of age, body composition analysis revealed that increase in body size was appropriate as reflected by LM and bone density similar to matched term controls without an increase in fat mass. No child had severe cognitive developmental delay using a cutoff score of 70. Inpatient growth and increased receipt of MOM correlated with favorable growth and body composition outcomes. Positive outcomes as shown in this study to confirm postdischarge safety of an EHM diet during hospitalization.
\end{abstract}

Keywords: premature infants, human milk, nutrition, growth, body composition, neurodevelopment

\footnotetext{
${ }^{1}$ Department of Pediatrics, Section of Neonatology, Baylor College of Medicine, Texas Children's Hospital, Houston, Texas, USA. USA.

${ }^{2}$ Department of Pediatrics, Section of Neonatology, University of Oklahoma Health Sciences Center, Oklahoma City, Oklahoma,

${ }^{3}$ USDA/ARS Children's Nutrition Research Center, Department of Pediatrics, Baylor College of Medicine, Houston, Texas, USA.

${ }^{4}$ Department of Pediatrics, Section of Nutrition, King Chulalongkorn Memorial Hospital, The Thai Red Cross Society, Bangkok, Thailand.

${ }^{5}$ Pediatric Nutrition STAR, Department of Pediatrics, Faculty of Medicine, Chulalongkorn University, Bangkok, Thailand.

${ }^{6}$ Department of Pediatrics, Dell Medical School, Dell Pediatric Research Institute, University of Texas at Austin, Austin, Texas, USA.

(C) Erynn M. Bergner et al., 2020; Published by Mary Ann Liebert, Inc. This Open Access article is distributed under the terms of the Creative Commons License (http://creativecommons.org/licenses/by/4.0), which permits unrestricted use, distribution, and reproduction in any medium, provided the original work is properly cited.
} 


\section{Introduction}

D IETS CONTAINING HUMAN MILK (HM) have many benefits for preterm infants. ${ }^{1}$ Mother's own milk (MOM) improves both short- and long-term outcomes, many of which are enhanced in a dose/response fashion. ${ }^{1,2}$ Donor human milk (DHM) is less studied but has been shown to decrease rates of necrotizing enterocolitis (NEC). ${ }^{3}$ Despite unknowns, the American Academy of Pediatrics recommends that pasteurized DHM be used when MOM is unavailable in high-risk infants, with priority given to those infants $<1,500 \mathrm{~g}$ birth weight (BW).

An exclusive human milk-based (EHM) diet (consisting of MOM or DHM fortified with a pasteurized DHM-based fortifier) provides an entirely HM-based approach in the modern era of fortification for preterm infants. In multicenter randomized control trials, an EHM diet has been shown to significantly reduce $\mathrm{NEC}^{5,6}$ and parenteral nutrition days ${ }^{6}$ when compared with bovine-containing diets. In addition to finding significant reductions in NEC, a recent multicenter retrospective cohort study also demonstrated decreased mortality, late onset sepsis, retinopathy of prematurity, and bronchopulmonary dysplasia when an EHM diet was compared with a bovine-based diet. ${ }^{7}$ However, a single-center randomized control trial suggested that the routine use of HM-based fortifier over bovine-based fortifier does not improve feeding intolerance in a setting with high MOM use and donor milk supplementation and found no difference in NEC rates. ${ }^{8}$

The study of the long-term effects of nutritional interventions in the neonatal intensive care unit (NICU) is imperative as early growth ${ }^{9,10}$ and nutrition ${ }^{10}$ have been postulated to program the body in a manner that influences future metabolic health and disease. Specifically, improved NICU growth has been associated with improved neurodevelopmental outcomes. ${ }^{11,12}$ Despite this knowledge, postnatal growth restriction remains a pervasive problem for preterm infants. Reports exist showing almost $90 \%$ of very low BW infants having growth restriction, defined as a weight less than the 10th percentile, upon NICU discharge. ${ }^{13,14}$ Concern has arisen that catch-up growth in preterm infants, especially in small-for-gestational-age infants, may lead to increased adiposity and risk of future metabolic syndrome. ${ }^{15}$ To date, only one report has provided data showing that an EHM diet led to appropriate catch-up growth without metabolic consequences in premature infants measured at 2 years of age, ${ }^{16}$ and two small studies ${ }^{17,18}$ have found no difference in neurodevelopmental outcomes of infants who received an EHM diet in comparison to those that received bovine-based HM fortifiers. Thus, the appropriate balance between neonatal growth's impact on future body composition and neurodevelopmental outcomes needs more investigation.

This pilot study aimed to evaluate the postdischarge growth, body composition, and neurodevelopmental outcomes of a cohort of infants $\leq 1,250 \mathrm{~g}$ BW who received an EHM diet in the NICU and explore their relationship with both inpatient growth rates and the amount of MOM received. We hypothesized that infants receiving an EHM diet while in the NICU would achieve appropriate catch-up growth by 2 years of age as evidenced by anthropometric z-scores, appropriate body composition demonstrating normal lean mass (LM) rather than increased adiposity, and neurodevelopmental outcomes within normal limits.

\section{Materials and Methods}

We prospectively followed a cohort of infants $\leq 1,250 \mathrm{~g}$ BW who received an EHM diet while admitted to the NICU at Texas Children's Hospital (Houston, TX). Subjects were initially recruited from the cohort that comprised Hair et al.'s ${ }^{19}$ study on in-hospital growth. Recruitment was then expanded to the next consecutively born infants $\leq 1,250 \mathrm{~g} \mathrm{BW}$ admitted to the study institution to increase the sample size seen in follow-up to $\sim 50$ subjects. Inclusion criteria were premature infants ( $<37$ weeks gestation) with a $\mathrm{BW} \leq 1,250 \mathrm{~g}$ who received an EHM diet in the NICU until $\sim 34$ weeks postmenstrual age (PMA). Exclusion criteria were failure to achieve enteral feeds by 4 weeks of age, major congenital anomalies, and clinically significant congenital heart disease. MOM or DHM was fortified with a pasteurized DHM-based fortifier (Prolact $+\mathrm{H}^{2} \mathrm{MF}^{\circledR}$, Industry, CA) at an additional +4 $\mathrm{kcal} / \mathrm{oz}$ once enteral feeding volume reached $60 \mathrm{~mL} / \mathrm{kg} / \mathrm{d}$. Feeds were advanced to $+6 \mathrm{kcal} / \mathrm{oz}$ when volume reached $100 \mathrm{~mL} / \mathrm{kg} / \mathrm{d}$. If weight gain did not average $15 \mathrm{~g} / \mathrm{kg} / \mathrm{d}$ within a week after full enteral feedings were established, fortification was advanced to $+8 \mathrm{kcal} / \mathrm{oz}$.

As per institution practices, infants in this study were transitioned off the EHM diet at $\sim 34$ weeks PMA. Upon discharge, infants received HM complemented by 2-3 feedings per day of a $22 \mathrm{kcal} / \mathrm{oz}$ enriched ready-to-feed formula for a goal of $110-130 \mathrm{kcal} / \mathrm{kg} / \mathrm{d}$. If MOM was unavailable after discharge, infants received $22 \mathrm{kcal} / \mathrm{oz}$ enriched formula for all feeds. Infants received enriched formula as an outpatient until deemed appropriate to transition to routine term $20 \mathrm{kcal} / \mathrm{oz}$ formula by their primary care provider.

The Institutional Review Board of Baylor College of Medicine and Affiliated Hospitals approved this study, and it is registered at ClinicalTrials.gov (NCT01483079). Written informed consent was obtained from parents before participation in the study.

Two outpatient study visits occurred at 12-15 months corrected age (CA) (visit 1) and at 18-22 months CA (visit 2). At visits 1 and 2, anthropometric measurements were recorded and parents gave an interim medical history and a nutrition history of the infant since discharge. In addition, visit 2 included body composition by dual-energy X-ray absorptiometry (DXA) and neurodevelopmental evaluation. Weight, length, and head circumference (HC) measurements at birth and hospital discharge were assigned corresponding z-scores based on Fenton growth curves, ${ }^{20}$ while those at visits 1 and 2 were converted to z-scores for CA based on World Health Organization 2006 growth reference. $^{21}$ The study's registered dietitian analyzed diet histories to determine typical nutrient intake at visits 1 and 2 using Nutrition Data System for Research nutrient analysis software (Minneapolis, MN).

Body composition was measured by DXA (Delphi A model; Hologic, Bedford, MA; V12.1). This modality has been widely studied in pediatrics and has demonstrated high accuracy and precision. ${ }^{22}$ Measurements were obtained for bone mineral content (BMC) and bone mass density (BMD), body fat mass (FM), LM, and fat-free mass (FFM) using infant mode scanning. Fat mass index (FMI) and lean mass index were calculated as FM or LM in kilograms divided by the square of height in meters $\left(\mathrm{kg} / \mathrm{m}^{2}\right) .{ }^{23} \mathrm{DXA}$ data from a 
matched historical group of healthy term children were obtained for comparison with the study subjects to evaluate and compare body composition parameters. All children in this group were at least 37 weeks GA at birth, and had been involved in research protocols requiring healthy children. Each subject in the preterm study cohort was matched with a subject in the term group based on age, race, gender, weight, and height at the time of body composition analysis. The matching was carried out using the MatchIt package ${ }^{24}$ within the R statistical software environment. ${ }^{25}$

The Bayley Scales of Infant and Toddler Development III (BSID-III) was used to evaluate neurodevelopment and was administered by the same certified tester for all subjects. ${ }^{26}$ BSID scores have been validated in many studies to determine rates of developmental delay in preterm infants. ${ }^{11,27}$

Comparisons were carried out through the two independent samples $t$-test for continuous outcomes and Fisher's exact test for categorical outcomes. For body composition outcomes, comparisons of the preterm cohort with matched healthy term controls were made using paired $t$-tests. Neurodevelopmental outcomes were compared with the defined mean and standard deviation (SD) $(100 \pm 15)$ of the BSID-III $^{26}$ through a one-sample $t$-test. We assessed the relationship of inpatient growth and percentage of MOM received with the visits 1 and 2 growth, body composition, and neurodevelopmental outcomes using Pearson's correlation coefficient and linear regression analysis. SAS version 9.4 (SAS Institute, Inc., Cary, NC) was used for data analysis.

\section{Results}

Demographic data and baseline characteristics of the subjects are presented in Table 1. Fifty-one infants (51/161, $32 \%$ ) participated in visit 1 , and 44 infants returned at visit 2 , 34 of which were able to have body composition analysis completed. Details on the flow of subjects from enrollment through visit 2 are summarized in Supplementary Figure S1. Gestational age at birth was $27.8 \pm 2.6$ weeks and BW was $893 \pm 204 \mathrm{~g}$. All infants received the EHM diet while inpatient. Although our protocol was to wean off the EHM diet at 34 weeks PMA, the average age of transitioning from the EHM diet to including cow milk fortifier or formula was $36.3 \pm 1.3$ weeks. Infants averaged appropriate weight and length gain velocities while inpatient with $21.2 \pm 3.5 \mathrm{~g} / \mathrm{day}$ and $1.0 \pm 0.2 \mathrm{~cm} /$ week from birth to discharge. $\mathrm{HC}$ velocity was slightly slower than desired at $0.7 \pm 0.2 \mathrm{~cm} /$ week during the same time period, although this is similar to historical HC velocity. There was no difference in nutritional intake among infants at visit 1 or visit 2 .

A higher percentage of infants seen in follow-up were receiving $\mathrm{HM}$ at NICU discharge than eligible infants that were not evaluated in follow-up (55\% versus $35 \%$ at visit 1 , $57 \%$ versus $36 \%$ at visit $2, p=0.026$ and 0.020 , respectively). There were no other significant differences in baseline characteristics between the cohort seen in follow-up and those that were not (Supplementary Tables S1 and S2).

Growth outcomes at visits 1 and 2 are shown in Table 2. Incidence of weight being less than 10th percentile increased during NICU hospitalization from $22 \%$ of infants at birth born small for gestational age to $54 \%$ of infants less than 10th percentile at discharge. This improved to $35 \%$ of infants less
Table 1. Baseline Characteristics of SubJeCts $(N=51)$

\begin{tabular}{|c|c|}
\hline Gestational age at birth (weeks) ${ }^{\mathrm{a}}$ & $27.8 \pm 2.6$ \\
\hline Male, $n(\%)$ & $30(59)$ \\
\hline $\begin{array}{l}\text { Race, white/black/Hispanic/ } \\
\text { other, } n\end{array}$ & $15 / 18 / 14 / 4$ \\
\hline \multicolumn{2}{|l|}{ Birth } \\
\hline Weight $(\mathrm{g})^{\mathrm{a}}$ (z-score) & $893 \pm 204(-0.47 \pm 1.0)$ \\
\hline Length $(\mathrm{cm})^{\mathrm{a}}(\mathrm{z}$-score $)$ & $34.2 \pm 3.2(-0.47 \pm 1.3)$ \\
\hline $\mathrm{HC}(\mathrm{cm})^{\mathrm{a}}$ (z-score) & $24.2 \pm 2.0(-0.43 \pm 1.0)$ \\
\hline \multicolumn{2}{|l|}{ Discharge } \\
\hline Weight $(\mathrm{g})^{\mathrm{a}}$ (z-score) & $2,753 \pm 871(-1.5 \pm 1.2)$ \\
\hline Length $(\mathrm{cm})^{\mathrm{a}}(\mathrm{z}$-score $)$ & $46.2 \pm 3.9(-1.8 \pm 1.4)$ \\
\hline $\mathrm{HC}(\mathrm{cm})^{\mathrm{a}}$ (z-score) & $33.0 \pm 2.4(-1.2 \pm 1.1)$ \\
\hline \multicolumn{2}{|l|}{ Growth rate, birth to discharge } \\
\hline Weight $(g / \text { day })^{a}$ & $21.2 \pm 3.5$ \\
\hline Length $(\mathrm{cm} / \text { week })^{\mathrm{a}}$ & $1.0 \pm 0.2$ \\
\hline $\mathrm{HC}(\mathrm{cm} / \text { week })^{\mathrm{a}}$ & $0.7 \pm 0.2$ \\
\hline \multicolumn{2}{|c|}{ Growth restriction ( $<10$ th percentile), $n(\%)$} \\
\hline At birth & $11(22)$ \\
\hline At discharge & $28(54)$ \\
\hline \multicolumn{2}{|l|}{ Bronchopulmonary dysplasia, $n(\%)$} \\
\hline Moderate/severe & $19(37)$ \\
\hline \multicolumn{2}{|l|}{ Intraventricular hemorrhage, $n(\%)$} \\
\hline Any & $9(18)$ \\
\hline Grade 3/4 & $1(2)$ \\
\hline Late onset sepsis, $n(\%)$ & $8(16)$ \\
\hline \multicolumn{2}{|l|}{$\mathrm{NEC}, n(\%)$} \\
\hline Medical & $0(0)$ \\
\hline Surgical & $0(0)$ \\
\hline $\begin{array}{l}\text { Spontaneous intestinal perforation, } \\
n(\%)\end{array}$ & $1(2)$ \\
\hline$\%$ feeds mother's milk in NICU ${ }^{\mathrm{a}}$ & $72.3 \pm 35.5$ \\
\hline Calories at discharge $[\mathrm{kcal} / \mathrm{kg} / \mathrm{d}]^{\mathrm{a}}$ & $122 \pm 12$ \\
\hline $\begin{array}{l}\text { Received HM feeds postdischarge, } \\
n(\%)\end{array}$ & $28(55)$ \\
\hline PMA at discharge $(\text { weeks })^{\mathrm{a}}$ & $40.4 \pm 5.0$ \\
\hline Length of stay (days) ${ }^{\mathrm{a}}$ & $88 \pm 43$ \\
\hline
\end{tabular}

${ }^{\mathrm{a}}$ Mean \pm standard deviation.

Percentiles and $z$-scores based on Fenton 2013 growth curve. ${ }^{20}$

$\mathrm{HC}$, head circumference; HM, human milk; NEC, necrotizing enterocolitis; NICU, neonatal intensive care unit; PMA, postmenstrual age.

than 10th percentile at visit 1 and further improved to $30 \%$ of subjects less than 10th percentile at visit 2 .

Comparisons of z-scores for weight, length, and $\mathrm{HC}$ at birth, discharge, visit 1, and visit 2 are shown in Figure 1. Z-scores at discharge were lower $(p<0.05)$ than those at birth for all growth parameters. At 12-15 months CA, weight Z-scores remained lower $(p=0.048)$ but length $(p=0.217)$ and $\mathrm{HC}(p=0.835) \mathrm{z}$-scores were minimally different from birth. At $18-22$ months CA, z-scores for weight ( $p=0.548)$, length $(p=0.707)$, and $\mathrm{HC}(p=0.358)$ were similar to birth $\mathrm{z}$-scores.

Measurements of body composition by DXA for the preterm cohort and matched term controls are shown in Table 3. The study group and the term matched control group showed no significant differences between any of the DXA measurements, either while evaluating the entire cohort or when evaluating males and females separately. In the preterm 
Table 2. Growth Outcomes at Visit 1 (12-15 Months Corrected Age) and Visit 2 (18-22 Months Corrected Age) for Premature Infants Who Received an Exclusive Human Milk-Based Diet In the Neonatal Intensive Care Unit

\begin{tabular}{lcc}
\hline & Visit $1(\mathrm{n}=51)$ & Visit $2(\mathrm{n}=44)$ \\
\hline Corrected age (months) & $14.0 \pm 1.0$ & $19.4 \pm 1.3^{\mathrm{a}}$ \\
Weight (kg) (z-score) & $9.1 \pm 1.4(-0.7 \pm 1.3)$ & $10.3 \pm 1.3(-0.6 \pm 1.2)$ \\
Length (cm) (z-score) & $75.4 \pm 3.6(-0.8 \pm 1.4)$ & $81.8 \pm 5.0(-0.4 \pm 1.8)$ \\
HC (cm) (z-score) & $45.6 \pm 1.7(-0.4 \pm 1.2)$ & $46.8 \pm 1.7(-0.3 \pm 1.3)$ \\
Growth velocity & $14.78 \pm 3.37^{\mathrm{b}}$ & $7.76 \pm 2.76^{\mathrm{c}}$ \\
Weight (g/day) & $0.48 \pm 0.06^{\mathrm{b}}$ & $0.27 \pm 0.14^{\mathrm{c}}$ \\
Length (cm/week) & $0.21 \pm 0.04^{\mathrm{b}}$ & $0.05 \pm 0.02^{\mathrm{c}}$ \\
HC (cm/week) & $18(35)$ & $13(30)$ \\
Weight $<10$ th percentile, $n(\%)$ &
\end{tabular}

Z-scores and percentiles based on 2006 World Health Organization Growth Curves. ${ }^{21}$

Mean \pm standard deviation.

${ }^{\mathrm{b}}$ Change in growth parameter from NICU discharge to visit 1.

${ }^{\mathrm{c}}$ Change in growth parameter from visits 1 to 2 .

$\mathrm{HC}$, head circumference; NICU, neonatal intensive care unit.

cohort, weight gain (g/day) from birth to discharge had positive correlations with BMC $(r=0.44, p=0.009), \mathrm{LM}$ $(r=0.39, p=0.024)$, and FFM $(r=0.394, p=0.021)$ at $18-22$ months CA. For every $5 \mathrm{~g} /$ day increase in weight gain during the NICU hospitalization, there is a $19.8 \mathrm{~g}$ predicted increase in BMC at 18-22 months CA $(p=0.009)$. Likewise, for every $5 \mathrm{~g}$ /day increase in NICU growth, the predicted increase in LM at $18-22$ months CA is $0.4 \mathrm{~kg}(p=0.02)$. Increasing percent of MOM received was also correlated with decreased FM $(r=-0.376, p=0.029)$, fat percentage $(r=-0.34, p=0.046)$, and FMI $(r=-0.39, p=0.022)$. For every $10 \%$ increase in MOM, there is an anticipated $0.08 \mathrm{~kg}$ reduction in FM $(p=0.029)$ at $18-22$ months CA.

The composite mean BSID-III scores at 18-22 months CA were as follows: cognitive (97.6 \pm 13.4$)$, language $(84.7 \pm 14.0)$, and motor $(93.1 \pm 10.7)$, (mean \pm SD). Eight infants $(18.2 \%)$ had BSID-III language composite scores $<70$ (2 SDs below the mean), and two infants (4.5\%) had motor composite scores $<70$. None of the infants had cognitive composite scores $<70$ (severe impairment), and six subjects $(13.6 \%)$ had composite scores $<85$ (mild/moderate cognitive impairment). In comparison to the standard com- posite mean of 100 defined by BSID-III, ${ }^{26}$ the composite mean of the cohort were significantly different for language $(p<0.001)$ and motor $(p=0.001)$ but not cognitive scores $(p=0.241)$. There were no significant correlations between inpatient growth or postnatal growth and neurodevelopmental scores. Increasing amounts of MOM received during the neonatal hospitalization had a near significant correlation with improved language receptive raw scores $(r=0.298$, $p=0.052$ ).

\section{Discussion}

This study is the first to concurrently evaluate long-term growth, body composition, and neurodevelopmental outcomes of preterm infants in the modern era of fortification who received an entirely HM-based approach to nutrition until $\sim 36$ weeks PMA. We found that premature infants receiving an EHM diet had appropriate postdischarge growth based on a return to birth z-scores by $12-15$ months CA for length and $\mathrm{HC}$ and by 18-22 months CA for weight. Infants had a similar percentage of body fat and LM compared with matched term controls, with adequate bone mineralization,
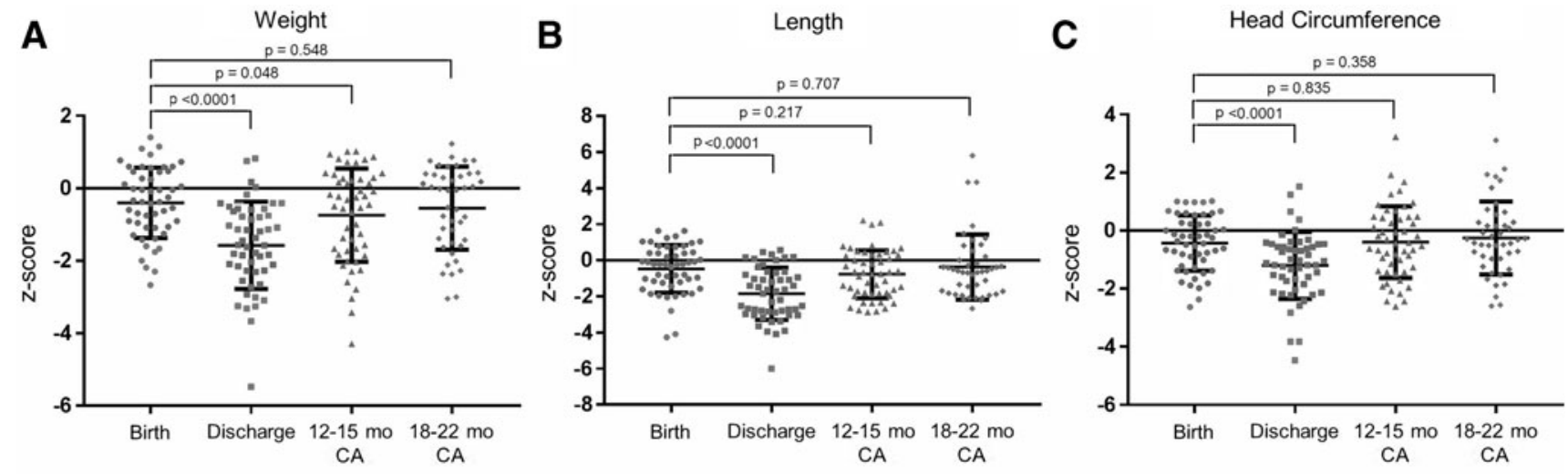

FIG. 1. Comparison of z-scores between birth, discharge, visit 1 (12-15 months CA), and visit 2 (18-22 months CA) for (A) weight, (B) length, and (C) head circumference. CA, corrected age. 
Table 3. Body Composition at Visit 2 (18-22 Months Corrected Age) of Premature Infants Who Received an Exclusive Human Milk-Based Diet in the Neonatal Intensive Care Unit Compared with a Healthy Term Matched Reference Population

\begin{tabular}{|c|c|c|c|c|c|c|}
\hline & \multicolumn{2}{|c|}{$A l l$} & \multicolumn{2}{|c|}{ Females } & \multicolumn{2}{|c|}{ Males } \\
\hline & $\begin{array}{c}\text { Study } \\
\text { subjects, } \mathrm{n}=34\end{array}$ & $\begin{array}{c}\text { Matched } \\
\text { controls, } \mathrm{n}=34\end{array}$ & $\begin{array}{c}\text { Study } \\
\text { subjects, } \mathrm{n}=15\end{array}$ & $\begin{array}{c}\text { Matched } \\
\text { controls, } \mathrm{n}=15\end{array}$ & $\begin{array}{c}\text { Study } \\
\text { subjects, } \mathrm{n}=19\end{array}$ & $\begin{array}{c}\text { Matched } \\
\text { controls, } \mathrm{n}=19\end{array}$ \\
\hline Age (years) & $1.85 \pm 0.10^{\mathrm{a}}$ & $1.83 \pm 0.20$ & $1.86 \pm 0.11$ & $1.85 \pm 0.20$ & $1.84 \pm 0.10$ & $1.82 \pm 0.20$ \\
\hline Weight (kg) & $10.4 \pm 1.3$ & $10.8 \pm 1.5$ & $10.1 \pm 1.4$ & $10.3 \pm 1.8$ & $10.7 \pm 1.1$ & $11.1 \pm 1.1$ \\
\hline Height $(\mathrm{cm})$ & $82.5 \pm 5.4$ & $82.7 \pm 5.7$ & $82.9 \pm 6.2$ & $82.8 \pm 7.1$ & $82.1 \pm 4.7$ & $82.6 \pm 4.4$ \\
\hline $\mathrm{BMC}(\mathrm{g})$ & $282.4 \pm 36.0$ & $284.3 \pm 53.5$ & $275.6 \pm 38.1$ & $272.5 \pm 55.0$ & $287.7 \pm 34.3$ & $293.6 \pm 51.8$ \\
\hline $\operatorname{BMD}\left(\mathrm{g} / \mathrm{cm}^{2}\right)$ & $0.316 \pm 0.02$ & $0.314 \pm 0.03$ & $0.314 \pm 0.02$ & $0.306 \pm 0.03$ & $0.318 \pm 0.03$ & $0.320 \pm 0.04$ \\
\hline FM (kg) & $2.16 \pm 0.80$ & $2.40 \pm 0.78$ & $2.03 \pm 0.88$ & $2.35 \pm 0.68$ & $2.26 \pm 0.73$ & $2.44 \pm 0.86$ \\
\hline FMI $\left(\mathrm{kg} / \mathrm{m}^{2}\right)$ & $3.17 \pm 1.17$ & $3.51 \pm 1.07$ & $2.89 \pm 1.11$ & $3.43 \pm 0.77$ & $3.40 \pm 1.20$ & $3.57 \pm 1.27$ \\
\hline $\mathrm{LM}(\mathrm{kg})$ & $8.34 \pm 0.82$ & $8.61 \pm 1.07$ & $8.03 \pm 0.79$ & $8.18 \pm 1.17$ & $8.58 \pm 0.78$ & $8.95 \pm 0.87$ \\
\hline LMI $\left(\mathrm{kg} / \mathrm{m}^{2}\right)$ & $12.32 \pm 1.29$ & $12.59 \pm 1.23$ & $11.75 \pm 1.33$ & $11.91 \pm 0.86$ & $12.77 \pm 1.10$ & $13.13 \pm 1.23$ \\
\hline Fat $\%$ & $19.60 \pm 5.38$ & $21.06 \pm 4.96$ & $18.97 \pm 5.94$ & $21.62 \pm 3.70$ & $20.08 \pm 5.01$ & $20.62 \pm 5.84$ \\
\hline
\end{tabular}

$p$-Values $>0.05$ for all.

${ }^{\mathrm{a}}$ Mean \pm standard deviation.

BMC, bone mineral content; BMD, bone mass density; CA, corrected age; FM, fat mass; FMI, fat mass index; LM, lean mass; LMI, lean mass index.

and no cognitive BSID-III scores $<70$ at $18-22$ months CA. Inpatient growth correlated with improved future anthropometrics, LM, FFM, and BMC while increased MOM exhibited a dose/response relationship to decreased FM.

\section{Growth}

A Cochrane review concluded that preterm infants who were fed with formula had superior in-hospital growth compared with those fed with DHM, but there were no differences in long-term growth, and body composition was not addressed. ${ }^{3}$ Only 4 of the 11 studies reviewed, however, used fortified DHM. With an EHM diet, we found that inpatient growth velocity positively correlated to weight, length, and $\mathrm{HC}$ at $12-15$ months $\mathrm{CA}$ and to weight and $\mathrm{HC}$ at 18-22 months CA, demonstrating appropriate long-term growth postdischarge at about 2 years of age. Additionally, our study demonstrates a $30 \%$ postnatal growth restriction rate in comparison to $40 \%$ for extremely low BW $(<1,000 \mathrm{~g})$ infants previously reported by Dusick et al. ${ }^{13}$ This comparison, however, is limited by the standard of nutrition care at that time before an era of EHM diet, which included cow milk fortifiers and premature infant formula. More recently, Henriksen et al. documented that among very low BW infants receiving $\mathrm{HM}$ fortified with a cow milk-based HM fortifier, 33\% had growth restriction at birth, which increased to $\sim 60 \%$ at discharge. ${ }^{28}$

\section{Bone mineralization}

Extremely premature infants are at high risk for osteopenia of prematurity as they are born before peak in-utero bone mineral accrual. ${ }^{29}$ Infants in our study had acceptable bone mineralization at follow-up, as both BMC and BMD showed no differences from a matched reference population of healthy term children. Fewtrell et al. ${ }^{30}$ performed an analysis of premature infants who received MOM and found that those receiving $>90 \%$ MOM had significantly higher whole-body skeletal size and BMC at 20 years of age than those that received $<10 \%$ MOM. This evidence is supported by findings that bone mass at 9-11 years is also positively related to duration of lactation that preterm infants received. ${ }^{31}$

\section{Body composition}

Prior analyses of the body composition of preterm infants have found increased and aberrant adiposity at term CA, which represents a risk factor for future metabolic and cardiovascular disease. ${ }^{32}$ In addition, there is evidence that excessive catch-up growth may be associated with increased risk of childhood obesity. ${ }^{33}$ In a long-term evaluation of small-for-gestational-age infants, Ezzahir et al. ${ }^{34}$ showed that catch up growth most adversely affected adult body mass index when it occurred later in life, hypothesizing that weight gain when restricted to a normal period of rapid adipose gain such as infancy may not be as deleterious to future metabolic outcomes. In our study, weight gain (g/day) from birth to discharge was positively correlated with increased LM and FFM, but not FM, at 18-22 months CA, demonstrating that infants were gaining appropriate LM instead of adiposity. Our study's finding of a correlation to a more favorable future body composition indicates potential promising impacts of early fortification with an entirely HM-based approach to nutrition for preterm infants and further underlines the need to support adequate in-hospital growth.

As the percentage of MOM our cohort received in the hospital increased, FM, fat percentage, and FMI at 18-22 months CA decreased, displaying a possible protective effect of HM against adiposity. Previously, MOM intake has been associated with a reduction of adolescent and adult obesity rates in former term infants ${ }^{35}$ and a decrease in rates of future metabolic syndrome in the preterm population. ${ }^{2}$ These findings support continued efforts to maximize MOM use within the context of an EHM.

\section{Neurodevelopmental outcomes}

An important connection exists between appropriate growth in terms of body composition and neurodevelopment. 
Ramel et al. $^{36}$ found that increased LM, but not fat mass, during infant hospitalization was associated with improved cognitive and motor scores at 12 months CA. Similar to body composition abnormalities, preterm infants have a higher risk of impaired neurodevelopmental outcomes than term infants. ${ }^{37}$ Preterm infants fed MOM have been shown to have improved neurodevelopmental outcomes, ${ }^{2}$ however DHM has not been demonstrated to have an independent effect. ${ }^{38}$

At 18-22 months CA, all the infants in our study had cognitive BSID-III scores $>70$. BSID-III means were consistent with previous reports ${ }^{17,18}$ of the neurodevelopmental outcomes of an EHM diet at 18 months CA. In relation to other diets, Vohr et al. ${ }^{39}$ recently published a study of the neurodevelopmental outcomes of $<1,250 \mathrm{~g} \mathrm{BW}$ infants born within the same time frame as our cohort. Infants in that study received MOM fortified with a powdered cow milk-derived fortifier and did not receive DHM. Our cohort had comparable cognitive (97.6 \pm 13.4 versus 90.2 \pm 14$)$, language (84.7 \pm 14 versus $87.3 \pm 17)$, and motor $(93.1 \pm 10.7$ versus $90.8 \pm 15)$ BSID-III composite scores to Vohr et al.' ${ }^{39}$ data. O'Connor et al. ${ }^{38}$ also recently published a randomized control trial of infants of slightly higher BW $(<1,500 \mathrm{~g})$ examining the BSID-III scores at 18 months CA of preterm infants who had been randomized to receive DHM (fortified with a bovine-based fortifier) or preterm formula when MOM was unavailable. Our EHM diet cohort also had BSID-III composite mean scores comparable to O'Connor et al.'s ${ }^{38}$ DHM (cognitive 92.9, language 87.3, and motor 91.8) and preterm formula (cognitive 94.5, language 90.3, motor 94.0) groups. While exact comparisons to the literature are complicated by differences in medical practices and comorbidities, these results are promising and highlight the importance for continued long-term studies of an EHM diet.

\section{Limitations}

This study is a small single-center pilot study with relatively short-term follow-up. Given the small sample size, there is limited statistical power to detect differences between groups. Thus, the lack of body composition differences between the infants in this cohort and term matched controls requires further investigation in larger studies powered for this outcome. Utilizing the estimated difference in LM between the term matched controls and preterm infants seen in follow-up in our study, future studies would need 225 participants per group to achieve $80 \%$ statistical power to detect a difference between term and preterm infants' LM at the 5\% significance level.

In addition, the significant increase in percentage of subjects who were receiving HM at NICU discharge indicates a possible selection bias toward infants that received more overall exposure to MOM in the follow-up cohort. Given the positive associations between MOM and outcomes demonstrated in this study, this difference may have influenced results. As it is an observational study, confounding could also influence some of the associations reported and, thus, provides a limitation in the ability to infer causality among them.

\section{Conclusions}

This study is the first to provide a comprehensive report of the long-term growth, body composition, and neurodeve- lopmental outcomes of premature infants $\leq 1,250 \mathrm{~g} \mathrm{BW}$ who received an EHM diet in the NICU. In addition to catching up on BW, length, and $\mathrm{HC}$ z-scores by 2 years of age, body composition through DXA demonstrated that the increase in body size was appropriate as reflected by LM and bone density similar to matched term controls. There was no excessive increase in fat mass or adiposity, rather an appropriate increase in bone density, LM, and fat mass was seen showing overall optimal growth by 2 years.

Overall findings suggest that this cohort of infants who received an EHM diet in the NICU are doing well at 2 years of age. As this pilot study was limited by a small sample size, further studies powered to detect differences in outcomes and long-term comparisons to other diets are still needed. Correlations with favorable outcomes continue to emphasize the importance of preventing growth restriction and promoting MOM in the preterm population. As we continue to optimize nutritional practices in the NICU and investigate an entirely HM-based approach for the diets of preterm infants, it is important to follow the potential impact of these changes on health and development long term.

\section{Acknowledgments}

The authors would like to thank the following people for their invaluable assistance with the project: Marie Turcich, Maryse Laurent, Vilma Cardova, Janice Betancourt, Mandy Belfort, Jonathan Davies, Laura Gollins, Lynda Tang, and Michael LeCompte. They would like to thank the Bad Pants Open Fund at Texas Children's Hospital for supporting this project.

\section{Authors' Contributions}

Each author made substantial contributions to conception and design, acquisition of data, or analysis and interpretation of data. All authors either drafted the article or revised the content critically and provided final approval of the article.

\section{Disclosure Statement}

A.B.H. receives research support from Fresenius Kabi for the Randomized SMOF Study and Prolacta Bioscience for an unrelated study in cardiac infants and the human milk cream study. K.M.H. receives speaker honoraria from Prolacta Bioscience and Abbott Nutrition. No industry funding was received for this study. The remaining authors declare no potential conflict of interest.

\section{Funding Information}

This project was funded by the Bad Pants Open Fund at Texas Children's Hospital.

\section{Supplementary Material}

Supplementary Figure S1

Supplementary Table S1

Supplementary Table S2

\section{References}

1. American Academy of Pediatrics Section on Breastfeeding. Breastfeeding and the use of human milk. Pediatrics 2012; 129:e827-e841. 
2. Schanler RJ. Outcomes of human milk-fed premature infants. Semin Perinatol 2011;35:29-33.

3. Quigley M, Embleton ND, McGuire W. Formula versus donor breast milk for feeding preterm or low birth weight infants. Cochrane Database Syst Rev 2018;6:CD002971.

4. American Academy of Pediatrics Committe on Nutrition, Section on Breastfeeding, Committee on Fetus and Newborn. Donor human milk for the high-risk infant: Preparation, safety, and usage options in the united states. Pediatrics 2017; 139:e20163440.

5. Sullivan S, Schanler RJ, Kim JH, et al. An exclusively human milk-based diet is associated with a lower rate of necrotizing enterocolitis than a diet of human milk and bovine milk-based products. J Pediatr 2010;156:562.e561567.e561.

6. Cristofalo EA, Schanler RJ, Blanco CL, et al. Randomized trial of exclusive human milk versus preterm formula diets in extremely premature infants. J Pediatr 2013:1592-1595.

7. Hair AB, Peluso AM, Hawthorne KM, et al. Beyond necrotizing enterocolitis prevention: Improving outcomes with an exclusive human milk-based diet. Breastfeed Med 2016; 11:70-74.

8. O'Connor DL, Kiss A, Tomlinson C, et al. Nutrient enrichment of human milk with human and bovine milkbased fortifiers for infants born weighing <1250 g: A randomized clinical trial. Am J Clin Nutrit 2018;108:108-116.

9. Barker DJ. The developmental origins of adult disease. J Am Coll Nutrit 2004;23(6 Suppl.):588s-595s.

10. Lucas A. Long-term programming effects of early nutrition-implications for the preterm infant. J Perinatol 2005; 25(Suppl. 2):S2-S6.

11. Ehrenkranz RA, Dusick AM, Vohr BR, et al. Growth in the neonatal intensive care unit influences neurodevelopmental and growth outcomes of extremely low birth weight infants. Pediatrics 2006;117:1253-1261.

12. Franz AR, Pohlandt F, Bode H, et al. Intrauterine, early neonatal, and postdischarge growth and neurodevelopmental outcome at 5.4 years in extremely preterm infants after intensive neonatal nutritional support. Pediatrics 2009;123:e101-e109.

13. Dusick AM, Poindexter BB, Ehrenkranz RA, et al. Growth failure in the preterm infant: Can we catch up? Semin Perinatol 2003;27:302-310.

14. Clark RH, Thomas P, Peabody J. Extrauterine growth restriction remains a serious problem in prematurely born neonates. Pediatrics 2003;111(5 Pt. 1):986-990.

15. Thureen PJ. The neonatologist's dilemma: Catch-up growth or beneficial undernutrition in very low birth weight infants-what are optimal growth rates? J Pediatr Gastroenterol Nutrit 2007;45(Suppl. 3):S152-S154.

16. Visuthranukul C, Abrams SA, Hawthorne KM, et al. Premature small for gestational age infants fed an exclusive human milk-based diet achieve catch-up growth without metabolic consequences at 2 years of age. Arch Dis Child Fetal Neonatal Ed 2019;104:F242-F247.

17. Colacci M, Murthy K, DeRegnier RO, et al. Growth and development in extremely low birth weight infants after the introduction of exclusive human milk feedings. Am $J$ Perinatol 2017;34:130-137.

18. Hopperton KE, O'Connor DL, Bando N, et al. Nutrient enrichment of human milk with human and bovine milkbased fortifiers for infants born $<1250 \mathrm{~g}$ : 18-month neurodevelopment follow-up of a randomized clinical trial. Curr Dev Nutrit 2019;3:nzz129.
19. Hair $\mathrm{AB}$, Hawthorne KM, Chetta KE, et al. Human milk feeding supports adequate growth in infants $</=1250$ grams birth weight. BMC Res Notes 2013;6:459.

20. Fenton TR, Kim JH. A systematic review and meta-analysis to revise the Fenton growth chart for preterm infants. $B M C$ Pediatr 2013;13:59.

21. World Health Organization. Child Growth Standards: The WHO Child Growth Standards. 2006. Available at www .who.int/childgrowth/standards/en (accessed August 20, 2019).

22. Chan GM. Performance of dual-energy X-ray absorptiometry in evaluating bone, lean body mass, and fat in pediatric subjects. J Bone Miner Res 1992;7:369-374.

23. Wells JC, Cole TJ. Adjustment of fat-free mass and fat mass for height in children aged 8 y. Int J Obes Relat Metab Disord 2002;26:947-952.

24. Ho DE, Imai K, King G, et al. MatchIt: Nonparametric preprocessing for parametric casual inference. J Stat Softw 2011;42:1-28.

25. R: A Language and Environment for Statistical Computing [computer program]. Vienna, Austria: R Foundation for Statistical Computing, 2016.

26. Bayley N. Bayley Scales of Infant and Toddler Development, 3rd ed. San Antonio, TX: Harcourt Assessment, Inc., 2006.

27. Vohr BR, Poindexter BB, Dusick AM, et al. Beneficial effects of breast milk in the neonatal intensive care unit on the developmental outcome of extremely low birth weight infants at 18 months of age. Pediatrics 2006;118:e115e123.

28. Henriksen C, Westerberg AC, Ronnestad A, et al. Growth and nutrient intake among very-low-birth-weight infants fed fortified human milk during hospitalisation. $\mathrm{Br} J \mathrm{Nutr}$ 2009;102:1179-1186.

29. Fewtrell M. Early nutritional predictors of long-term bone health in preterm infants. Curr Opin Clin Nutrit Metab Care 2011;14:297-301.

30. Fewtrell MS, Williams JE, Singhal A, et al. Early diet and peak bone mass: 20 year follow-up of a randomized trial of early diet in infants born preterm. Bone 2009;45:142-149.

31. Backstrom MC, Maki R, Kuusela AL, et al. The long-term effect of early mineral, vitamin $\mathrm{D}$, and breast milk intake on bone mineral status in 9- to 11-year-old children born prematurely. J Pediatr Gastroenterol Nutr 1999;29:575582.

32. Roggero $\mathrm{P}$, Gianni ML, Amato $\mathrm{O}$, et al. Is term newborn body composition being achieved postnatally in preterm infants? Early Hum Dev 2009;85:349-352.

33. Ong KK, Ahmed ML, Emmett PM, et al. Association between postnatal catch-up growth and obesity in childhood: Prospective cohort study. BMJ (Clin Res Ed) 2000;320: 967-971.

34. Ezzahir N, Alberti C, Deghmoun S, et al. Time course of catch-up in adiposity influences adult anthropometry in individuals who were born small for gestational age. $\mathrm{Pe}$ diatr Res 2005;58:243-247.

35. Owen CG, Martin RM, Whincup PH, et al. Effect of infant feeding on the risk of obesity across the life course: A quantitative review of published evidence. Pediatrics 2005; 115:1367-1377.

36. Ramel SE, Gray HL, Christiansen E, et al. Greater early gains in fat-free mass, but not fat mass, are associated with improved neurodevelopment at 1 year corrected age for prematurity in very low birth weight preterm infants. J Pediatr 2016;173:108-115. 
37. Marlow N, Wolke D, Bracewell MA, et al. Neurologic and developmental disability at six years of age after extremely preterm birth. $N$ Engl J Med 2005;352:9-19.

38. O'Connor DL, Gibbins S, Kiss A, et al. Effect of supplemental donor human milk compared with preterm formula on neurodevelopment of very low-birth-weight infants at 18 months: A randomized clinical trial. JAMA 2016;316: 1897-1905.

39. Vohr B, McGowan E, McKinley L, et al. Differential effects of the single-family room neonatal intensive care unit on 18- to 24-month bayley scores of preterm infants. J Pediatr 2017;185:42.e41-48.e41.
Address correspondence to: Amy B. Hair, $M D$

Department of Pediatrics Section of Neonatology Baylor College of Medicine Texas Children's Hospital 6621 Fannin Street, Suite WT-6104 Houston, TX 77030

USA

E-mail: abhair@texaschildrens.org 